\title{
Diagnosis and Intervention Program for Burnout Syndrome in Primary and Secondary Teachers at a School in Pereira
}

\author{
Juan Fernando Matajudios Carmona ${ }^{1, *}$, Cristian Fernán Muñoz Muñoz ${ }^{2}$ \\ ${ }^{1}$ Department of Human Sciences and Health, Faculty of Psychology, University Corporation Minuto de Dios UNIMINUTO, Colombia \\ ${ }^{2}$ Department of Human Sciences and Health, Faculty of Psychology; University of Minuto de Dios University Teacher UNIMINUTO, \\ Colombia
}

Received December 22, 2020; Revised February 24, 2021; Accepted March 16, 2021

\begin{abstract}
Cite This Paper in the following Citation Styles
(a): [1] Juan Fernando Matajudios Carmona, Cristian Fernán Muñoz Muñoz, "Diagnosis and Intervention Program for Burnout Syndrome in Primary and Secondary Teachers at a School in Pereira," Universal Journal of Public Health, Vol. 9, No. 2, pp. 75 - 82, 2021. DOI: 10.13189/ujph.2021.090206.
\end{abstract}

(b): Juan Fernando Matajudios Carmona, Cristian Fernán Muñoz Muñoz (2021). Diagnosis and Intervention Program for Burnout Syndrome in Primary and Secondary Teachers at a School in Pereira. Universal Journal of Public Health, 9(2), 75 - 82. DOI: 10.13189/ujph.2021.090206.

Copyright $\bigcirc 2021$ by authors, all rights reserved. Authors agree that this article remains permanently open access under the terms of the Creative Commons Attribution License 4.0 International License

\begin{abstract}
The aim objective of this research was to develop and measure the effectiveness of a cognitive behavioral program developed by the authors based on a cognitive behavioral model, in order to counter burnout syndrome in teachers dedicated to the primary and secondary education sector of the city of Pereira, which consists of eight sessions that took place over a period of two months ( 8 weeks) lasting two hours for each session and applied in a population of eighty primary and secondary teachers from a private school in the city of Pereira, Colombia, during the second half of 2019. The study consisted of a quantitative methodology and quasi-experimental model, with pretest and postest measurements. With a control group of 36 teachers an experimental group consisting of 44 teachers, a sociodemographic labor questionnaire and the Maslach Burnout Inventory were used. The formation of the experimental and control groups was carried out in a homogeneous way with teachers presenting high, medium and low level of burnout. The realization of the statistics was done through the SPSS25 program in its version for Windows and effectiveness results were found for the intervention with demonstrative significance greater than $50 \%$ in its three components, Emotional Exhaustion, Low Personal Realization and Depersonalization.
\end{abstract}

Keywords Mental Stress, Teacher, Burnout Syndrome

\section{Introduction}

The human being is subject to various dysfunctions and alterations that can affect his mental, physical and psychological health. Another studies show an important relationship between psychosocial risk factors at work and different types of disorders such as chronic work stress (Wang et al, 2009; Schultz and others, 2010), so it is very important to assess the presence of burnout in education workers, since, in addition to being necessary, it is urgent, prevent and intervene, to mitigate its effects, since it reduces the quality of life of teachers, which can sometimes lead to extreme death.

Many other studies show the consequences of psychosocial risk factors at work that are too closely linked to the condition of Burnout Syndrome, such as absenteeism at work (Darr and Johns, 2008), conflicts in the relationship between work and family (Kinman and Jones, 2008); (Kawakami and Tsutsumi, 2010), sleep disorders (Heponiemi et al, 2009) and other disorders related to mental health (Bourbonnais, Brisson, Vinet, Vézina, \& Lower, 2006; Lehr, Hillert, \& Keller, 2009; Wang et al, 2009), in addition to depressive disorders (Ylipaavalniemi et al., 2005); (Lehr et al., 2009; Rugulies, Bültmann, Aust, \& Burr, 2006) and anxiety disorders. 
This leads to a great interest in the study of Burnout Syndrome at present, which has facilitated an expansion of his study, in which research has been carried out in various professional fields, such as education (Marrau, 2004; Valério, Amorim and Moser, 2009). When teachers are professionals who can be considered at high risk of suffering from this syndrome. (Terán \& Botero, 2012); Therefore, since the 1960s, based on Beck's contributions, researchers have carried out very important Cognitive-Behavioral interventions, which until now have been insufficient, since, in most of these studies, they have made the Measurements of efficacy, but the diagnosis of the participants have not been systematized, to have comparative data of the process before and after the interventions carried out.

For this reason, since the 1990s, workers' health problems in different areas and aspects have been a cause of concern in different international organizations, such as the World Health Organization, the International Labor Organization and the Panamerican Health Organization.

This concern has been developing due to the great changes in development, which have caused a great impact on living conditions, risk factors and working conditions, which affect the mental and physical health of the working population. (Tennassee and Eijkemans; 1999). Since then, these organizations, together with the World Bank and the International Monetary Fund, have worked on the development of government structures that allow understanding of the importance of workers' mental health, the environment and sustainable human development.

In the Global Plan on Workers' Health, 2008-2017, the need to intervene in the health of workers as a group within organizational structures is highlighted, based on the concept that their mental health is not conditioned solely by the organization, but also due to social and individual factors, in addition to access to health services. (WHO; 2007), this plan includes some priorities such as the application of intervention plans to control and prevent psychosocial risks in the environment, based on the continuous improvement of evaluation processes and the management of health risks. (WHO; 2003).

According to Aguilera and others (2008), the intervention processes must be integrated through four phases corresponding to Diagnosis, Planning, Implementation and Evaluation, where each of them is interdependent and of utmost importance for the achievement of the proposed objectives. However, occupational health evaluations emphasize the greater importance of evaluation. Since the evaluation is the one that allows to objectively assess the limitations and the scope of each implemented strategy to make new decisions.

The World Labor Organization points out that, of every 10 workers in industrialized countries, one suffers from pathologies related to stress, anxiety or depression, which causes important economic and social consequences

\section{(Aguilera et al., 2008).}

What allows from a biopsychosocial approach to express the biological consequences formed by stress, as follows; the response made by the body varies depending on whether it is in a phase of initial tension in which there is a total speed of the organism in which the commutations that originate are easily remissible, if the cause is isolated or improved in a stage of prolonged stress, in which the symptoms become permanent and the disease is generated. In this way, a specific event and its experience are related to the physiological responses that are manifested, which allows locating stressful environmental factors and considering their consequences in the individual aspect. For this reason, it is possible to denote that cognitive processes generate signals from the cerebral cortex to the hypothalamus and then the vegetative (automatic) nervous system, from there to the marrow of the adrenal glands, which respond by releasing adrenaline and norepinephrine, which are the so-called hormones of the stress; These hormones are carried by our body and allow us to fight or flight. (Toates, 1995).

It is due to this affectation that, for Colombia, only until 2008, a law was implemented that through RESOLUTION 002646 through which the provisions were established and the responsibilities for the identification, evaluation, prevention, intervention and monitoring were defined permanent exposure to psychosocial risk factors at work and to determine the origin of pathologies caused by occupational stress (Acero, 2018). But only through resolution 2404 of July 2019 issued through the Ministry of Labor, the Battery of Assessment Instruments and psychosocial risk factors and the technical guide for the promotion and prevention of these were adopted, adding in its article 1 the protocol of Promotion and intervention for Burnout. (Ministry of Labor; 2019).

Cognitive-behavioral interventions have been too helpful for the intervention process in cases of depression, stress, and anxiety; This supports Beck's work, which corresponds to several years of research and clinical practice in the field of mental health. For this reason, for the authors, cognitive therapy allows us to understand a series of changes that have been taking place gradually in the behavioral sciences, such as, for example, various techniques that have been based on the application of logic through rules of the evidence, which have served to further develop and improve cognitive-behavioral intervention techniques. (Beck, AT.; 1967; Beck, AT.; 1976; López RM. 2000), which also Cabrera and others (2005), express that the interventions based on the Cognitive-Behavioral model have shown very positive effects in the treatment of individuals with chronic fatigue syndrome.

Among the research related to teachers at the international level, we can highlight those carried out in Spain and other countries, in which various aspects such 
as frequency, predisposing factors and various associates, ways of coping, models emphasized in prevention. in addition to job satisfaction and quality of life. (Aris, 2009; Duran and others, 2005; Moriana and Herruzo, 2004).

For Latin America, several related studies have been carried out, including that of (Yslado M., M., Z., \& F., 2014), who in his study "Program of Diagnosis and Intervention of Burnout Syndrome in Primary Education teachers of the districts of Huarez and Independencia". Whose general objective in this study was describe the frequency and characteristics of Burnout Syndrome in primary education teachers with work experience equal to or greater than five years, from public institutions in the districts of Huarez and Independencia, in addition to planning and evaluating the results of a psychoeducational intervention program. With a sample of 133 teachers, of which 8 teachers were selected, according to the inclusion criteria. The survey and a questionnaire that included demographic aspects and the Maslach-ED scale were used. Some conclusions were: 1) the teachers present "Burnout" in the initial phases $(78.2 \%)$, intermediate $(2.3 \%)$ and final $(19.5 \%) .2)$ the psychoeducational intervention program applied to Burnout cases in the final stage (VII) has been significantly effective in reducing emotional fatigue $(83.3 \%)$.

Dra. Adla Jaik Dipp, MC Roberto Villanueva Gutiérrez, MC Martha Eva García Salas, MC Jorge Alberto Tena Flores, in (2011); They carried out an investigation that was characterized by being quantitative, non-experimental, cross-sectional and descriptive-correlational, in which 1,823 students and 118 professors from a total of 27 higher-level institutions in the state of Durango, Mexico participated. Among the results, a teaching performance characterized as very good and a level of mild exhaustion syndrome stand out. There is no correlation between teacher performance and burnout syndrome at a higher level.

In Colombia, more specifically Muñoz, C. \& Piernagorda in (2011) They carried out a study that identified the relationship between coping strategies and Burnout syndrome in primary and secondary teachers from a private educational institution in the municipality of Cartago (Colombia), the results of which indicate a presence of the syndrome, with a high prevalence in the $12 \%$ of the population; medium, at $70 \%$ and low, at $18 \%$. Coping strategies that are positively related to the syndrome are compliance, emotional avoidance, waiting, seeking an alternative, and seeking social support. Those that are negatively related include: finding alternatives and seeking professional support. Muñoz, C; Correa, C \& Matajudios, J.F. (2020) they carried out an-studio in which they found in a population: 274 teachers; $15 \%$ of the population suffers from high level of Burnout. Lack of Professional Realization is high, Emotional Exhaustion and Depersonalization in average score.

Further, Padilla and others (2009) studied Burnout
Syndrome (SAP) or "Burnout" to determine the prevalence and characteristics associated with SAP in public schools in Bogotá. Where a cross-sectional design, survey type, was carried out in three public schools in Bogotá. Teachers were assessed using the Maslach Inventory for Professional Burnout Syndrome and a questionnaire designed to assess sociodemographic, personal and work factors. According to the results found, the SAP has a prevalence of $15.4 \%$ for teachers and could increase to $29.7 \%$ if we consider that two of the three SAP domains are above the 30th percentile. $25.3 \%$ of teachers presented a high degree of emotional fatigue. The prevalence of SAP was lower in teachers older than 55 years, with 21 to 30 years of experience; in those who only work one day, and in those who have management positions. It would be less frequent in married teachers and those with more children.

Therefore, this research is justified, since it responds to national and international policy guidelines on public and mental health, which promote the reduction of exclusion presented by teachers affected by mental or occupational health problems and has an impact on the preservation of human resources within organizations, as active and potential capital, providing knowledge for the preparation of guidelines in the educational, labor and mental health fields of the region in which this research was carried out.

\section{Materials and Methods}

\section{Shows}

A random sample was taken with 80 primary and secondary teachers from a private school in the city of Pereira, Risaralda; Colombia, of which 54.4\% correspond to women and $45.6 \%$ to men, 3.8 with a level of technician or technologist, $96.2 \%$ with a degree of professionalization, $10.6 \%$ with a degree of specialization, $2.6 \%$ with a master's degree and $1.3 \%$ with a doctorate level. To perform the Burnout Syndrome (SB) measurement, it is required to express that at a clinical level no score can determine its prevalence, however, it is established that high scores in Emotional Exhaustion and Depersonalization and low in Personal Accomplishment allow identifying the presence of the Syndrome from Burnout, where the sample unit size is valid, as supported by Castro, 1975; Milton and Tsokos, 1989; Polit and Hungler, 1994 and Hernández, Fernández and Baptista, 2006. A sample of 44 teachers was taken from this group as an experimental group and a control group of 36 teachers was left, from which the individuals with the highest scores for Burnout Syndrome were taken as the experimental group.

\section{Instruments}

The instrument used to collect the information, before 
and after the test. It is the Maslach Inventory for Burnout (MBI). This inventory measures the frequency or intensity of Burnout syndrome, which consists of 22 elements distributed in three subscales that in turn measure the three dimensions that make up the syndrome: Emotional Exhaustion, Depersonalization, and low Personal Accomplishment at work.

To determine the existence of the syndrome, the scale used by other authors (Mansilla, F, 2004, Seisdedos, 1997). Consequently, we base ourselves on the following values:

Table 1. Scales of Burnout Syndrome

\begin{tabular}{|c|c|c|c|}
\hline & High & Means, medium & Low \\
\hline Emotional Exhaustion & $>27$ & $19-26$ & $<18$ \\
\hline Depersonalization & $>10$ & $6-9$ & $<5$ \\
\hline Personal Accomplishment & $0-33$ & $34-39$ & $>40$ \\
\hline
\end{tabular}

Source: Maslach and Jasson

\section{Methodology}

The research methodology is quantitative, quasi-experimental, longitudinal, which includes measurements at the beginning and end of the study (Lerma, 2003).

\section{Data analysis}

For the analysis of the information, the SPSS statistic was used. In its version 25 for Windows.

Eight sessions of two hours each were scheduled in the intervention program, which was held weekly with a duration of 8 weeks (two months); during which didactic material was used for the identification and conceptualization of stress and Burnout Syndrome (SB).

\section{Intervention program}

The intervention and prevention program that was developed based on five strategies, which consist of stress control, communication improvement and development of self-help and interpersonal relationship attitudes, learning of cognitive resources, the practice of techniques to adapt to the environment and training of social skills. This intervention program is made up of eight sessions which take place over two months ( 8 weeks). These sessions are characterized by being techniques that provide tools to the individual that allow them to know how to manage chronic work stress and Burnout Syndrome on a physical and psychological level, since knowing how it works, the causes, effects and management alternatives help to counteract its consequences and prevent it.

This method consists of proposing effective and specific learning experiences to help participants detect negative thoughts, with which they manage to control the cause, effect and behavior relationship; allowing them to develop strategies to control intrusive thoughts, thus replacing deviant cognitions that alter existing false beliefs that predispose and distort stressful work experiences.

\section{Result}

According to the findings found in the population (table 3 ), it can be observed that in the measurement before the application of the intervention program, the following results were obtained, for the dimension of Emotional Exhaustion (46.2\%) of the teachers had low levels; (31.3\%) of the teachers have medium levels, while $(22.5 \%)$ of the teachers have high levels of Emotional Exhaustion. In the Personal Accomplishment dimension, (23.8\%) of the teachers have low levels; $(28.7 \%)$ of the teachers have medium levels, while $(47.5 \%)$ of the teachers have high levels of Personal Accomplishment and for the dimension of Depersonalization (48.8\%) of the teachers they have low levels; (28.7\%) of the teachers have medium levels, while $(22.5 \%)$ of the teachers have high levels of Depersonalization.

Table 2. Prevalence of Burnout Syndrome

\begin{tabular}{|c|c|c|c|c|c|}
\hline & N & Minimum & Maximum & Half & Dev. Deviation \\
\hline Emotional Exhaustion & 80 & 1 & 54 & 19.13 & 10,413 \\
\hline Personal Accomplishment & 80 & 10 & 48 & 38.43 & 7,209 \\
\hline Depersonalization & 80 & 0 & 24 & 6.92 & 5,320 \\
\hline N valid (per list) & 80 & & & & \\
\hline
\end{tabular}

Source: the authors

Table 3. Prevalence of Burnout Syndrome pretest (total group pretest)

\begin{tabular}{|c|c|c|c|c|}
\hline \multicolumn{1}{|c|}{} & Emotional Exhaustion & Personal Accomplishment & Depersonalization \\
\hline \multirow{4}{*}{ Valid } & Low & $46.2 \%$ & $23.8 \%$ & $48.8 \%$ \\
\cline { 2 - 5 } & Means, medium & $31.3 \%$ & $28.7 \%$ & $28.7 \%$ \\
\cline { 2 - 5 } & High & $22.5 \%$ & $47.5 \%$ & $22.5 \%$ \\
\cline { 2 - 5 } & Total & 100.0 & 100.0 & 100.0 \\
\hline
\end{tabular}

Source: The authors 
According to the data (table 4), the findings showed that in the dimension of Emotional Exhaustion (12.2\%) the teachers had low levels; $(38.3 \%)$ of the teachers have medium levels, while $(49.5 \%)$ of the teachers have high levels of Emotional Exhaustion. In the Personal Accomplishment dimension, $(50.8 \%)$ of the teachers have low levels; $(32.7 \%)$ of the teachers have medium levels, while $(16.5 \%)$ of the teachers have high levels of Personal Accomplishment and for the dimension of Depersonalization $(28.2 \%)$ of the teachers they have low levels; (48.4\%) of the teachers have medium levels, while $(23.4 \%)$ of the teachers have high levels of depersonalization.

According to the data (table 5), the findings showed that in the dimension of Emotional Exhaustion (80.9\%) the teachers had low levels; $(10.6 \%)$ of the teachers have medium levels, while $(8.5 \%)$ of the teachers have high levels of Emotional Exhaustion. In the Personal Accomplishment dimension, (8.5\%) of the teachers have low levels; (19.1\%) of the teachers have medium levels, while $(72.3 \%)$ of the teachers have high levels of Personal Accomplishment and for the dimension of Depersonalization (74.5\%) of the teachers have low levels; $(19.1 \%)$ of teachers have medium levels, while $(6.4 \%)$ of teachers have high levels of Depersonalization.

According to the data (table 6), the findings showed that in the dimension of Emotional Exhaustion (37.9\%) the teachers had low levels; $(21.4 \%)$ of the teachers have medium levels, while $(40.7 \%)$ of the teachers have high levels of Emotional Exhaustion. In the Personal Accomplishment dimension, (33.6\%) of the teachers have low levels; (35.7\%) of the teachers have medium levels, while $(30.7 \%)$ of the teachers have high levels of Personal Accomplishment and for the dimension of Depersonalization $(37.7 \%)$ of the teachers they have low levels; $(26.4 \%)$ of the teachers have medium levels, while $(45.9 \%)$ of the teachers have high levels of Depersonalization.

Table 4. Prevalence of Burnout Syndrome pretest (previous test experimental group)

\begin{tabular}{|c|c|c|c|c|c|}
\hline \multicolumn{2}{|c|}{} & Emotional Exhaustion & $\begin{array}{c}\text { Personal } \\
\text { Accomplishment }\end{array}$ & Depersonalization & N \\
\hline \multirow{4}{*}{ Valid } & Low & $12.2 \%$ & $50.8 \%$ & $28.2 \%$ & \\
\cline { 2 - 7 } & $\begin{array}{c}\text { Means, } \\
\text { medium }\end{array}$ & $38.3 \%$ & $32.7 \%$ & $48.4 \%$ & \\
\cline { 2 - 7 } & High & $49.5 \%$ & $16.5 \%$ & $23.4 \%$ & 444 \\
\cline { 2 - 7 } & Total & 100.0 & 100.0 & 100.0 & \\
\hline
\end{tabular}

Source: The authors

Table 5. Prevalence of Burnout Syndrome Posttest (experimental group after the test)

\begin{tabular}{|c|c|c|c|c|c|}
\hline \multicolumn{2}{|c|}{} & Emotional Exhaustion & $\begin{array}{c}\text { Personal } \\
\text { Accomplishment }\end{array}$ & Depersonalization & N \\
\hline \multirow{4}{*}{ Valid } & Low & $80.9 \%$ & $8.5 \%$ & $74.5 \%$ & 4 \\
\cline { 2 - 7 } & $\begin{array}{c}\text { Means, } \\
\text { medium }\end{array}$ & $10.6 \%$ & $19.2 \%$ & $19.1 \%$ & 4 \\
\cline { 2 - 7 } & High & $8.5 \%$ & $72.3 \%$ & $6.4 \%$ & 4 \\
\cline { 2 - 7 } & Total & 100.0 & 100.0 & 100.0 & 444 \\
\hline
\end{tabular}

Source: The authors

Table 6. Prevalence of Burnout Syndrome Posttest (control group, post-test)

\begin{tabular}{|c|c|c|c|c|c|}
\hline \multicolumn{2}{|c|}{} & $\begin{array}{c}\text { Emotional } \\
\text { Exhaustion }\end{array}$ & $\begin{array}{c}\text { Personal } \\
\text { Accomplishment }\end{array}$ & Depersonalization & N \\
\hline \multirow{4}{*}{ Valid } & Low & $37.9 \%$ & $33.6 \%$ & $37.7 \%$ & \\
\cline { 2 - 6 } & Means, medium & $21.4 \%$ & $35.7 \%$ & $26.4 \%$ & \\
\cline { 2 - 7 } & High & $40.7 \%$ & $30.7 \%$ & $35.9 \%$ & \\
\cline { 2 - 7 } & Total & 100.0 & 100.0 & 100.0 & 336 \\
\hline
\end{tabular}

Source: The authors 
Table 7. Prevalence of Burnout Syndrome (Comparison of the results of the experimental group after the application of the psychoeducational intervention program)

\begin{tabular}{|c|c|c|c|c|c|c|c|}
\hline & & Pretest & & & Posttest & & \\
\hline & High & $\begin{array}{l}\text { Means, } \\
\text { medium }\end{array}$ & Low & High & $\begin{array}{l}\text { Means, } \\
\text { medium }\end{array}$ & Low & $\begin{array}{c}\text { Difference for } \\
\text { Burnout } \\
\text { Syndrome } \\
\end{array}$ \\
\hline Emotional Exhaustion & $49.5 \%$ & $38.3 \%$ & $12.2 \%$ & $8.5 \%$ & $10.6 \%$ & $80.9 \%$ & $-68.7 \%$ \\
\hline Personal Accomplishment & $16.5 \%$ & $32.7 \%$ & $50.8 \%$ & $72.3 \%$ & $19.2 \%$ & $8.5 \%$ & $-55.8 \%$ \\
\hline Depersonalization & $23.4 \%$ & $48.4 \%$ & $28.2 \%$ & $6.4 \%$ & $19.1 \%$ & $74.5 \%$ & $-46.3 \%$ \\
\hline
\end{tabular}

Source: The authors

At the end of the application of the intervention program (table 7), it was found that there was significant differences in the evaluation of Burnout Syndrome on the component of Emotional Exhaustion in its high and Means medium level of - 68.7\%; in the Personal Accomplishment component in its Means medium and low level of - 55.8\% and the Depersonalization component in its High and Means medium level of - $46.3 \%$; before and after the application of the Intervention Program.

\section{Discussion}

This study was carried out to verify the efficacy of an Intervention Program designed by the authors, based on a Cognitive-Behavioral approach to counteract Burnout Syndrome in teachers, which was applied to a population of Primary and Secondary teachers, which were part of this study voluntarily; It should be noted that, in the short term, only eight weeks in this program was effective, reducing Burnout Syndrome.

This shows us that the application of the program decreased the feeling of Emotional Exhaustion a 68.7\%, also reducing the perception of low Personal Accomplishment a 55.8\%, thus reducing the Depersonalization evaluated in the participants a $46.3 \%$, between pre-test and post-test measurement.

The studies carried out show that there is a high prevalence of Burnout Syndrome in the studied sample, which evidences a mental health problem, understanding that stress is conditioned by the psychobiological characteristics of the individual and that it is generated by different labor stressors, individual and social, which intervene in the teacher's perception when carrying out his work, conceiving it as a process that is not satisfactory, neither by the teacher himself, nor by the administrative guidelines of the educational institutions, nor by society, as expressed by a study carried out by UNESCO. (Robalino and Korner, 2006).

In this sense, Padilla et al. (2009) in his studies with teachers from Bogotá and Muñoz MF and Piernagorda (2011); Muñoz MF and Correa Otalvaro C. (2012); express that there is a high prevalence of Burnout Syndrome, which confirms the findings obtained in this study, since the High and Means medium prevalence of Burnout Syndrome is
$50 \%$ in general, thus demonstrating the theory based on the model. Demand, control and social support for Robert Karasek and Tores Theorell (1996), in which it is stated that high work demands are the cause of work stress, demands for which teachers are not sufficiently prepared since they do not possess the cognitive, emotional and social skills to face these demands, which it causes the teacher to suffer emotional stress, which affects their mental health. (Theorell, T. \& Karasek, RA; 1996).

In this way, in the case of high levels of Depersonalization among teachers, it indicates that teachers perceive that they feel distanced in their teaching tasks from their students and colleagues since it is somewhat more routine due to their work condition., As it shows Cordeiro (2003), which I find in their work that the designated teachers present more advanced phases of Burnout than those hired

According to the results obtained in this investigation and accordance with the assumptions proposed by Beck (1967) and Beck. (1986), It was confirmed that when support is directed directly at individuals, in the search and the proportion of tools, it is possible to reduce unpleasant emotional reactions, which in turn allows the individual to modify their thoughts, thus reducing maladaptive behaviors.

The intervention model designed from a Cognitive-Behavioral model and implemented in Primary and Secondary teachers was effective in reducing the components that makeup Burnout Syndrome. This agrees with the results found in other investigations carried out in Colombia and Great Britain, among others, such as that of Arrivillaga and others (2007); that managed to reduce stress in hypertensive patients; Botero (2005), managed to reduce post-traumatic stress levels in members of the Colombian Armed Forces through cognitive behavioral therapy and Arrivillaga and others. (2007) in a quasi-experimental study carried out in Great Britain, where it was shown that Cognitive-Behavioral models are the ones that best contribute to improving the quality of working life, increasing the psychological resources of workers. 


\section{REFERENCES}

[1] Acero, DAS (2018). The employer's security obligation against stress at work. Comparative analysis between French law and Colombian law. U. Externado de Colombia.

[2] Aguilera, V. MA., Acosta F., Rodriguez RM., Madrigal MG., Pozos BE., (2008) Evaluation of socio-educational interventions and promotion of occupational health. Cuban magazine of health and work, pp. 50 - 60 .

[3] Aris, Nuria \& Redó,. (2009). Burnout Syndrome in teachers. Electronic Journal of Research in Educational Psychology. 7. 829-848. 10.25115 / ejrep.v7i18.1324.

[4] Arias López, HA, López, HAA, \& Tobar, RAT (2015). Cognitive personality and differential coping in anxiety and depression. Psychology; an International Journal of Psychology in the Orient, 9 (2), 49.

[5] Arrivillaga QM, Varela AMT, Cáceres de RDE, Correa SD, Holguín PLE. Efficacy of a cognitive-behavioural program for lowering blood pressure levels. Psychological Thought 2007; 3 (9): 33-49Bährer-Kohler, S. (2012). Burnout for Experts: Prevention in the Context of Living and Working. Springer Science \& Business Media.

[6] Beck, AT. (1967) Depression of Clinical Experimental and Theoretical Aspects. New York: Harper \& Row.

[7] Beck, AT. (1976) Cognitive Therapy and the Emotional Disorders. New York: International Universities Press.

[8] Beck, AT (1986): Cognitive approaches to anxiety disorders. In BF Shaw, ZV Segal, TM Vallis, \& F. Cashman (Eds.): Anxiety disorders: Psychological and biological perspectives. New York: Plenum Press.

[9] Bourbonnais, R., Brisson, C., Vinet, A., Vézina, M., \& Lower, A. (2006). Development and implementation of a participative intervention to improve the psychosocial work environment and mental health in an acute care hospital. Occupational and Environmental Medicine, 63 (5), 326334.

[10] Botero GC. Effectiveness of a cognitive-behavioural intervention for post-traumatic stress disorder in Colombian ex-combatants. Universitas Psychologica 2005; 4 (2): 205-219.

[11] Castro, L. (1975). 6. Experimental design without statistics. Uses and restrictions in their application to the behavioural sciences. Mexico: Ed. Trillas.

[12] Cabrera G., López R., Salinas T., Ochoa T., Marín C. and Haro G. (2005) Burnout syndrome in nursing personnel of a Mexican hospital. Rev. Med. IMSS 2005, 43 (1), pp11-16.

[13] Cordeiro, JA (2003). Prevalence of Burnout Syndrome in teachers. Results of a preliminary investigation. Psychology Magazine. Com, 7 (1).

[14] Darr, W., \& Johns, G. (2008). Work strain, health, and absenteeism: a meta-analysis. Journal of Occupational Health Psychology, 13 (4), 293-318.

[15] Dra. Adla Jaik Dipp, MC Roberto Villanueva Gutiérrez, MC Martha Eva García Salas, MC Jorge Alberto Tena Flores. (2011). Assessment of teaching performance and presence of Burnout in higher education teachers. Electronic Magazine
Educational Dialogues, 21.

[16] Duran, M., Extremera, N., Montalbán, F. and Rey, L. (2005), "Engagement and Burnout in the teaching field: Analysis of their relationships with job and life satisfaction in a sample of teachers", in Journal of Psychology of Work and Organizations. Vol. 21, n ${ }^{\circ} 1-2$, pp. 145-158.

[17] Hernández, R.; Fernández, C. and Baptista, P. (2006). Investigation methodology. Mexico: McGraw-Hill.

[18] Heponiemi, T., Kouvonen, A., Vänskä, J., Halila, H., Sinervo, T., Kivimäki, M., \& Elovainio, M. (2009). The association of distress and sleeping problems with physicians' intentions to change profession: the moderating effect of job control. Journal of Occupational Health Psychology, 14 (4), 365-373.

[19] Kawakami, N., \& Tsutsumi, A. (2010). Job stress and mental health among workers in Asia and the world. Journal of Occupational Health, 52 (1), 1-3.

[20] Kinman, G. \& Jones, F. (2008). Effort-reward imbalance, over-commitment and work-life conflict: testing an expanded model. Journal of Managerial Psychology, 23 (3), 236-251. DOI: 10.1108 / 02683940810861365

[21] Lehr, D., Hillert, A., \& Keller, S. (2009). What can balance the effort? Associations between effort-reward imbalance, overcommitment, and affective disorders in German teachers. International Journal of Occupational and Environmental Health, 15 (4), 374-384.

[22] Lopez RM. (2000) Burnout syndrome in healthcare personnel. Measuring instruments. Palliative Medicine.

[23] Mansilla Izquierdo, F. (2004). The labor amotivation syndrome. Annals of Psychiatry, 20 (10), 429-433.

[24] Marrau, CM (2004). Burnout syndrome and its possible consequences on the teaching worker.

[25] Milton, JS and Tsokos, JO (1989). 17. Statistics for biology and health sciences. Madrid: InterAmerican McGraw-Hill.

[26] Ministry of Labor (2019) Resolution 2404, Bogotá DC; Battery of instruments for the evaluation of psychosocial risk factors, protocol 1 of Promotion and intervention for Burnout. obtained from: https://www.mintrabajo.gov.co/do cuments/20147/59995826/Resolucion+2404+de+2019-+Ad opcion + bateria + riesgo + psicosocial $\% 2 \mathrm{C}+$ guia $+\mathrm{y}+$ protocolo s.pdf

[27] Moriana Elvira, Juan Antonio, \& Herruzo Cabrera, Javier (2004). Stress and burnout in teachers. International Journal of Clinical and Health Psychology, 4 (3), 597-621. [Consultation date June 17, 2020]. ISSN: 1697-2600. Available in: https://www.redalyc.org/articulo.oa?id=337/3 3740309

[28] Muñoz, C. and Piernagorda, D. (2011). Relationship between coping strategies and Burnout syndrome in 17 primary and secondary school teachers from an institution in Cartago, Valle. Psychogent, 14 (26), 389-402.

[29] Muñoz Muñoz, CF and Correa Otálvaro, CM (2012). Teacher burnout and coping strategies in primary and secondary teachers. Colombian Journal of Social Sciences, 3 (2), 226-242.

[30] Muñoz Cristian F; Correa Claudia M \& Matajudios Juan F 
(2020). Burnout syndrome and coping strategies in early childhood teachers. Rev. Espacios, Vol 41(37) art. 12. https://www.revistaespacios.com/a20v41n37/a20v41n37p1 2.pdf

[31] WHO (2003) Biosafety standards and procedures manual epidemiological surveillance committee (cove) division of human talent occupational health obtained from: http: //www.cepis.ops-oms.org / bvsacd / $\operatorname{cd} 49$ / gc-bioseguridad.pdf.

[32] WHO (2007) Workers' health: draft global action plan, Executive Board 120th session EB120 / 28 Rev.1. Pp. 1-9. Obtained from: http://apps.who.int/gb/ebwha/pdf_files/EB1 20/B120_28Rev1-sp.pdf

[33] Padilla M., AC, Gómez-Restrepo, C., Rodríguez, V., Dávila, M., Avella-García, CB, Caballero, A., Vives, A. ... Hernández, S. (January-March, 2009). Prevalence and characteristics of the professional burnout syndrome (SAP) in teachers from three public schools in Bogotá (Colombia). Colombian Journal of Psychiatry, 38 (1), 50-65.

[34] Polit, D. and Hungler, B. (1994). 24. Scientific research in health sciences. Mexico: InterAmerican McGraw-Hill.

[35] Robalino, M. and Korner, A. (2006). 25. Conditions of work and teaching health. Santiago de Chile: OREALC / UNESCO.

[36] Rugulies, R., Bültmann, U., Aust, B., \& Burr, H. (2006). Psychosocial work environment and incidence of severe depressive symptoms: prospective findings from a 5-year follow-up of the Danish work environment cohort study. American Journal of Epidemiology, 163 (10), 877-887.

[37] Seisdedos, N. (1997). Introduction, standardization and comments to the Spanish version of the MBI. In C. Maslach, \& SE Jackson (Eds.), MBI: Maslach's Burnout Introduction: "burn-out" syndrome due to care work stress. Madrid: Tea.

[38] Shultz, KS, Wang, M., Crimmins, EM \& Fisher, GG (2010). Age differences in the demand-control model of work stress an examination of data from 15 European countries. Journal of Applied Gerontology, 29 (1), 21-47. DOI: 10.1177 / 0733464809334286

[39] Theorell, T. \& Karasek, RA (1996). Current issues relating to psychosocial job strain and cardiovascular disease research. J Occup Health Psychol, 1 (1), 9-26

[40] Tennassee and Eijkemans (1999) Regional Plan for Workers' Health. WHO. Extracted from http://www.bvsde.paho.org/b vsast/e/fulltext/plansoes/planreg.html.

[41] Terán Rosero, AC, \& Botero Álvarez, C. (2012). Intra-labor psychosocial risks in teaching. Iberoamerican Journal of Psychology, 5 (2), 95-106. https://doi.org/10.33881/2027-1 786.rip. 5210

[42] Toates, FM (1995). Stress: conceptual and biological aspects. John Wiley \& Son Ltd.

[43] Valério, FJ, Amorim, C., \& Moser, AM (2009). A Burnout Syndrome in Teachers of Physical Education. Rev. of psychology Da IMED, 1 (1), 127-136.

[44] Valverde, M. (2007). X-ray of psychosocial risks. Practical management of occupational risks: integration and development of prevention management, 34, 32-35

[45] Wang, JL, Schmitz, N., Dewa, C. \& Stansfeld, S. (2009). Changes in perceived job strain and the risk of major depression: results from a population-based longitudinal study. American Journal of Epidemiology, 169 (9), 1085-1091. DOI: 10.1093 / Aje / Kwp037

[46] Ylipaavalniemi, J., Kivimäki, M., Elovainio, M., Virtanen, M., Keltikangas-Järvinen, L. \& Vahtera, J. (2005). Psychosocial work characteristics and incidence of newly diagnosed depression: a prospective cohort study of three different models. Social Science \& Medicine, 61 (1), 111-122. DOI: 10.1016 / j. socscimed.2004.11.038

[47] Yslado M., R., M., RY, Z., LN, \& F., RN (2014). Diagnosis and intervention program for Burnout syndrome in primary school teachers from Huaraz and Independencia districts (2009). Journal of Research in Psychology, 13 (1), 151. 